\title{
Comportamento fenológico de Sebastiania brasiliensis em Floresta Ombrófila Mista Aluvial
}

\author{
Marcos Vinícius Martins Bassaco ${ }^{1 *}$ \\ Antônio Carlos Nogueira ${ }^{2}$ \\ ${ }^{1}$ Faculdades Jaguariaíva, Rua Santa Catarina s/n, CEP 84200-000, Jaguariaíva - PR, Brasil \\ ${ }^{2}$ Universidade Federal do Paraná, Centro de Ciências Florestais e da Madeira \\ Programa de Pós-Graduação em Engenharia Florestal, Curitiba - PR, Brasil. \\ * Autor para correspondência \\ marcos.bassaco@hotmail.com
}

Submetido em 21/08/2018

Aceito para publicação em 21/03/2019

\section{Resumo}

Com a necessidade crescente do conhecimento biológico das espécies nativas para utilização em projetos de restauração de matas ciliares, este trabalho teve como objetivo a caracterização fenológica de Sebastiania brasiliensis, espécie arbórea arbustiva que ocorre na Floresta Ombrófila Mista Aluvial. Para isso, foi feito o acompanhamento de dez árvores no município de Araucária - PR, observando os eventos fenológicos reprodutivos e vegetativos. As fenofases reprodutivas e vegetativas apresentaram sazonalidade, sendo que as fases reprodutivas iniciaram no início do verão com o aparecimento dos primeiros botões florais e finalizaram com o fruto maduro no início da primavera, enquanto as fenofases vegetativas iniciaram no inverno, ocorrendo a queda das ocorrendo a queda das folhas, que retornaram na primavera. Embora as fenofases tenham apresentado a sazonalidade descrita, ela não apresentou correlação com as variáveis climáticas (temperatura, umidade relativa e precipitação) durante o período avaliado. Dessa forma pode-se concluir que as fenofases reprodutivas apresentam maior sazonalidade que as vegetativas, e que a espécie apresenta padrões fenológicos bem definidos, porém estudos com maior tempo de duração são indicados.

Palavras-chave: Autoecologia vegetal; Branquilho leiteiro; Floresta Ombrófila Mista Aluvial; Restauração florestal

\section{Abstract}

Phenology of Sebastiania brasiliensis in Subtropical Ombrophilous Alluvial Forest. In view of the growing need for biological knowledge of native species for use in riparian forest restoration projects, the aim of this work was the phenological characterization of Sebastiania brasiliensis, a shrubby tree species that occurs in the alluvial mixed ombrophilous forest. Accordingly, ten trees were monitored in the municipality of Araucária, PR, Brazil, observing the reproductive and vegetative phenological events. The reproductive and vegetative phenophases showed seasonality. The reproductive phases began in early summer with the appearance of the first floral buds and ended with the ripe fruit in early spring, while the vegetative phases began in the winter, occurring during leaf fall and with return of the leaves in spring. Although the phenophases exhibited the described seasonality, they did not show a correlation with climatic variables (temperature, relative humidity 
and precipitation) during the period evaluated. Therefore, we can conclude that reproductive phenophases have a higher seasonality than vegetative ones, and that the species has well-defined phenological patterns, but further studies of longer duration are indicated.

Key words: Alluvial Ombrophilous Forest; Branquilho-leiteiro; Forest restoration; Plant autoecology

\section{Introdução}

Diante da necessidade de técnicas de racionalização e de utilização dos recursos hídricos, torna-se imprescindível o conhecimento do comportamento das espécies de ambientes ciliares. Essa vegetação tem como função a manutenção da integridade e estabilidade da microbacia hidrográfica, representada por sua ação direta em uma série de processos importantes para o controle da qualidade e quantidade de água, como também para o controle da dinâmica vegetacional (RODRIGUES; GANDOLFI, 2004).

Esse tipo de ambiente, além de ser importante ambientalmente, também cria condições seletivas para a maioria das espécies vegetais, devido à deficiência de oxigênio, induzida pelo alagamento, e à ascensão do lençol freático. Assim, no decorrer do processo evolutivo, as plantas precisam alterar estruturas morfoanatômicas, para auxiliar na aeração interna, como também fazer alterações metabólicas, principalmente ativação de rotas anaeróbias para obtenção de energia (MEDRI et al., 2002). Logo, para enriquecer a diversidade de espécies com potencial de restauração de ambientes ciliares, o estudo da autoecologia das espécies torna-se fundamental. Para isso é importante iniciar a investigação identificando os fatores que influenciam a reprodução e a sobrevivência da espécie (MORELLATO et al., 2010).

Uma das ferramentas seria a fenologia, que possibilita um melhor entendimento da dinâmica da espécie e fornece suporte científico sobre aspectos da biologia no seu habitat natural, condições que não devem ser desprezadas para a aplicação de técnicas silviculturais seguras e inteligentes (ALENCAR, 1988; BELO et al., 2013). Além disso, trata-se de uma linha de pesquisa importante para entender o funcionamento dos ecossistemas florestais, sua conservação e manejo (MORELLATO, 1992; NEWSTROM et al., 1994; FERRERA et al., 2017).
O comportamento fenológico está muito ligado às condições climáticas da região, na qual algumas espécies florescem em períodos secos, em florestas tropicais secas, como um mecanismo de atrair polinizadores e deixar a fase de crescimento para os períodos chuvosos (BAWA et al., 2003). Por outro lado, em florestas tropicais úmidas, da Mata Atlântica e da Amazônia, algumas espécies florescem geralmente no início dos períodos chuvosos (MORELLATO et al., 2000), outras no fim do período seco e início das chuvas (PILON et al., 2015), enquanto outras podem florescer mais de uma vez ao ano e ainda existem espécies com mais de um ciclo por ano (BAWA et al., 2003). Dessa forma, as estratégias fenológicas, em nível de espécie e comunidade, ainda precisam ser mais bem estudadas, visto a grande variabilidade encontrada.

Diante disso, uma das espécies-chave é Sebastiania brasiliensis, que pode ser acrescentada à lista de espécies a ser utilizadas na restauração da Floresta Ombrófila Mista Aluvial (BARDDAL et al., 2004). Em face da potencialidade de utilização dessa espécie para fins de restauração de florestas ciliares, este trabalho visa identificar o comportamento fenológico reprodutivo e vegetativo dessa espécie.

\section{Material e Métodos}

\section{Área de estudo}

O estudo foi desenvolvido na foz do rio Verde (coordenadas: 25'36'01,93'S e 49 35'04,50'O, altitude: $864 \mathrm{~m})$, em um remanescente da Floresta Ombrófila Mista Aluvial, na planície do rio Iguaçu, no distrito de Guajuvira, município de Araucária, no Primeiro Planalto Paranaense.

Essa região fica sob domínio de clima subtropical úmido mesotérmico ( $\mathrm{Cfb}$ de Köeppen), com verões frescos, invernos rigorosos com geadas frequentes e precipitações bem distribuídas ao longo do ano, 
sem déficit hídrico. A temperatura média é de 17-18 ${ }^{\circ} \mathrm{C}$, com média mensal mínima de $12{ }^{\circ} \mathrm{C}$, máxima de $23{ }^{\circ} \mathrm{C}$ e precipitação média anual de 1.400 a 1.600 $\mathrm{mm}$, variando de 250 a $500 \mathrm{~mm} / \mathrm{mês}$ (MAACK, 1968). As características geomorfológicas e pedológicas da área amostrada são predominantemente formadas por Gleissolo Melânico, com "A" proeminente, com textura argilosa, em relevo plano, de fácil transbordamento, caracterizando um ambiente mal drenado (CURCIO, 2006).

$\mathrm{Na}$ época do estudo, houve pequenas diferenças nas variáveis climáticas em relação à série dos 10 anos anteriores (1999-2009). Sendo que a precipitação apresentou maior intensidade em relação à série histórica. A média dos últimos anos foi de $1.598 \mathrm{~mm}$ e na época de estudo foi de $2.326 \mathrm{~mm}$, com pequena variação na temperatura, ficando aproximadamente em $17{ }^{\circ} \mathrm{C}$ (Figura 1). (IAPAR, 2010). Os dados climáticos foram obtidos a partir de uma estação meteorológica localizada no município de Araucária - PR, aproximadamente a 20 km do local de estudo.

\section{Espécie estudada}

A espécie $S$. brasiliensis, pertencente à família Euphorbiaceae, é conhecida vulgarmente por leiteiro de folha fina ou branquilho-leiteiro, branquinho e pauleiteiro. Pode apresentar-se como arbusto ou árvore de 3 a $5 \mathrm{~m}$ de altura, glabro. Trata-se de uma espécie de luz difusa e seletiva higrófita, frequentemente desenvolve-se no interior dos capões e dos subbosques da Floresta Ombrófila Mista situados em solos úmidos em beira de rios; na restinga arbustiva do litoral, está situada em pequenas depressões, ocorrendo em formações que vão de Goiás até o Rio Grande do Sul, e nos países Uruguai, Argentina, Paraguai e Bolívia (REITZ, 1988).

FIGURA 1: Dados climáticos da região e da época de estudo (a); dados climáticos de 10 anos (entre 1999 e 2009) (b); temperatura média, mínima, máxima da época de estudo e comprimento do dia (2009 a 2010) (c). (Fonte: IAPAR, 2010; https://www. timeanddate.com/sun).

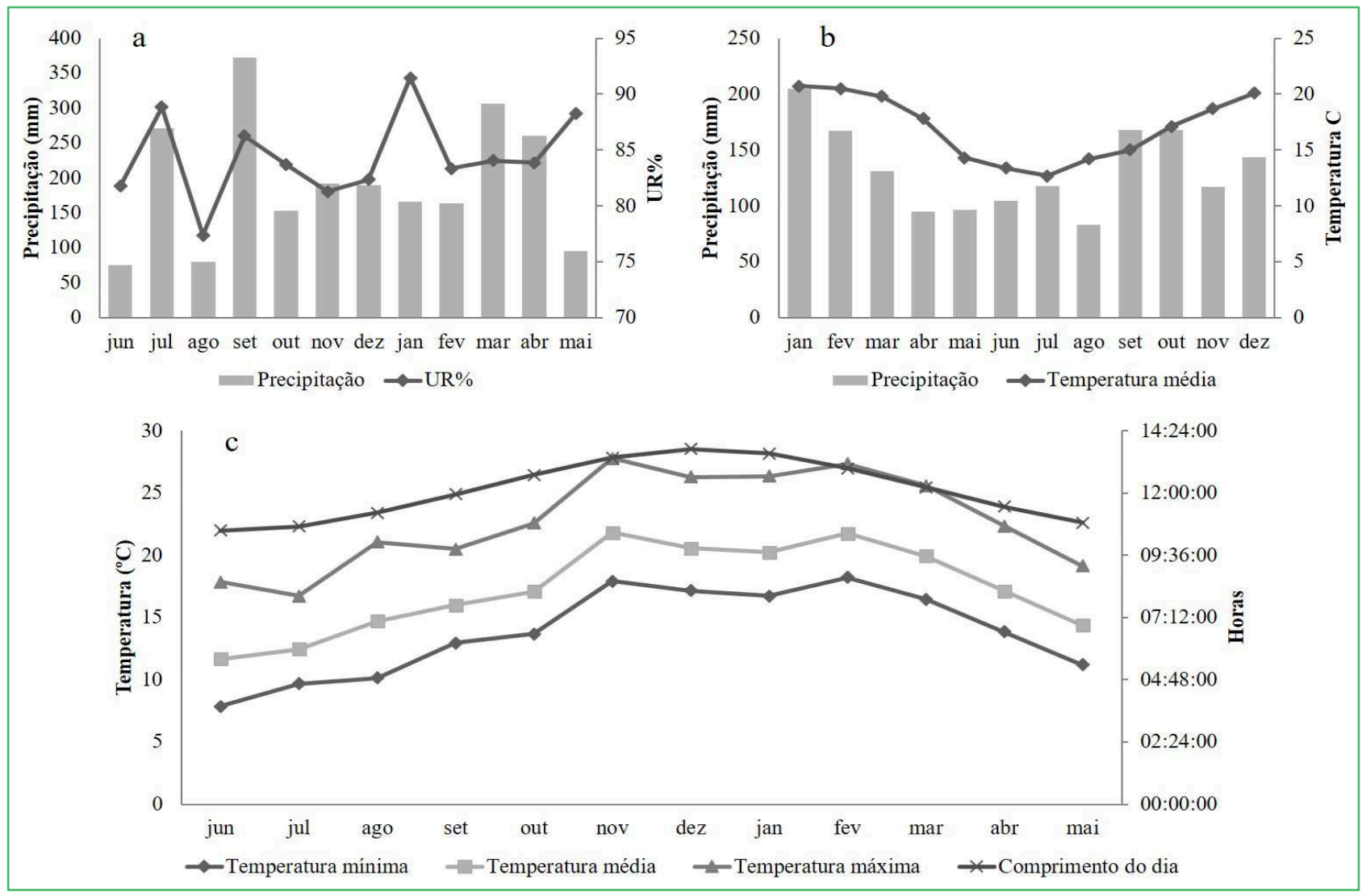




\section{Amostragem}

Foram selecionados dez indivíduos de $S$. brasiliensis com altura superior a $2 \mathrm{~m}$ de maneira aleatória ao longo do curso do rio para o acompanhamento fenológico, tamanho amostral considerado adequado por Fournier e Charpantier (1975). Todas as árvores selecionadas foram marcadas com tinta azul e numeradas com placas metálicas. Os dados fenológicos foram coletados durante um ano, de junho de 2009 a junho de 2010, com acompanhamento quinzenal. As observações fenológicas foram feitas a olho nu e com auxílio de um binóculo, quando necessário, e classificadas de acordo com as seguintes fenofases reprodutivas e vegetativas (adaptado de Fournier (1974) e Morellato et al. (1989)):

- Botão floral - aparecimento de pequenos botões, com tom amarelado, no ápice do galho, em forma de inflorescência.

- Flor aberta (antese) - considerou-se como flor aberta quando houve a abertura das pequenas pétalas brancas amareladas, na parte distal do galho, em forma de inflorescências.

- Frutos imaturos - considerou-se como frutos imaturos desde o momento do aparecimento de pequenas infrutescências em espigas de coloração verde, passando para frutos mais avermelhados e maiores, elipsóides, até o momento que começam a passar para tom verde escuro.

- Fruto maduro - foi considerado quando os frutos já estão totalmente formados, bem como as sementes em seu interior, ambos com coloração marrom e as sementes com mosqueados em tons claros.

- Queda foliar - considerou-se que uma árvore estava perdendo folhas quando: 1) suas folhas adquiriam um tom mais escuro; 2) se enrolavam; 3) quando caíam com facilidade ao ventar; 4) quando eram notadas falhas (sem folha) na copa ou nos galhos.

- Brotamento foliar - foi chamado de brotamento o período que se inicia com o aparecimento de pequenas folhas brilhantes, com cor verde clara ou levemente avermelhada.

\section{Análise dos dados}

Para verificar as épocas de ocorrência, pico e a duração de cada fenofase foram realizadas análises estatísticas circulares, utilizando o software ORIANA 3
(KOVACH, 2010). Nesse procedimento, os meses foram convertidos em ângulos com intervalos de $15^{\circ}$ para cada observação $\left(0^{\circ}=\right.$ primeira quinzena de junho/09, $15^{\circ}$ $=$ segunda quinzena de junho/09 até $345^{\circ}=$ segunda quinzena de junho/10), num total de 24 intervalos de $15^{\circ}$. Foi calculada a frequência de ocorrência dos indivíduos, em cada fenofase, dentro de cada ângulo. Dessa forma, foram calculados os seguintes parâmetros: ângulo médio (u), convertido em data média; comprimento do vetor médio (r), índice de sincronia: medida de concentração em torno do ângulo médio que indica se a fenofase é concentrada em torno de um pico e se há sincronia entre os indivíduos. Se o vetor for menor que 0,2 , considerase assincrônico, entre 0,2 a 0,6 , sincronia baixa, e acima de 0,6 , sincronia alta; também foi calculado o desvio padrão circular e intervalos de confiança. Adicionalmente, foi executado o teste de Rayleigh (z), que determina a significância do ângulo médio, testando se há sazonalidade nas fenofases (MORELLATO, et al., 2000; BENCKE; MORELLATO, 2002).

Calculou-se o percentual de intensidade de Fournier (1974). Nesse método, os valores obtidos em campo, através de uma escala intervalar semi-quantitativa de cinco categorias ( 0 a 4$)$ e intervalo de $25 \%$ entre cada categoria, permitem estimar a porcentagem de intensidade da fenofase em cada indivíduo. A intensidade foi avaliada quinzenalmente e, posteriormente, fez-se a soma dos valores de intensidade obtidos para todos os indivíduos e dividiu-se pelo valor máximo possível (número de indivíduos multiplicado por quatro). O valor obtido, que corresponde a uma proporção, é então multiplicado por 100, para transformá-lo em um valor percentual (BENCKE; MORELLATO, 2002).

As possíveis relações entre as intensidades de Fournier das fenofases e as variáveis climáticas do período de estudo: precipitação, temperatura média, umidade relativa e comprimento do dia foram correlacionadas entre os meses de avaliação das fenofases com os dados climáticos dos dois meses anteriores ao evento. Os cálculos foram feitos através de coeficientes de correlação de Spearman (rs), que foram considerados significativos quando os valores de "p" foram menores que 5\% (ZAR, 1998), para isso utilizou-se o programa BioEstat 5.3. 


\section{Resultados}

\section{Queda e brotamento foliar}

A queda e o brotamento foliar foram significativamente sazonais, ou seja, há ocorrência de sazonalidade com um padrão fenológico bem definido (Tabela 1).

O pico da atividade de queda foliar ocorreu no mês de junho, com baixa concentração em torno da data média, evidenciado pelo valor de $r$ igual a 0,59 , demonstrando uma baixa sincronia (Tabela 1). O brotamento foliar também apresentou baixa sincronia $(\mathrm{r}=0,41)$, sendo que o pico de atividade ocorreu no fim do mês de agosto (Tabela 1).

As árvores começavam a perder as folhas no mês de maio, atingindo uma intensidade de aproximadamente $40 \%$ nos meses de junho e julho (Figura 2e). Após esse período, iniciou o aparecimento do brotamento foliar, atingindo em agosto e setembro intensidade de $40 \%$ (Figura 2f).

TABELA 1: Resultado da análise circular dos eventos fenológicos de Sebastiania brasiliensis.

\begin{tabular}{cccccccc}
\hline \multirow{2}{*}{ Variáveis/Fenofases } & \multicolumn{7}{c}{ Sebastiania brasiliensis } \\
\cline { 2 - 7 } & Botões florais & Flor aberta & $\begin{array}{c}\text { Frutos } \\
\text { imaturos }\end{array}$ & $\begin{array}{c}\text { Frutos } \\
\text { maduros }\end{array}$ & Queda foliar & $\begin{array}{c}\text { Brotação } \\
\text { foliar }\end{array}$ \\
\hline Data média & $4 / \mathrm{fev}$ & $4 / \mathrm{mar}$ & $4 / \mathrm{jul}$ & $10 /$ out & $4 /$ jun & $25 /$ ago \\
Comprimento $(\boldsymbol{r})$ & $0,76^{*}$ & $0,76^{*}$ & $0,48^{*}$ & $0,98^{* *}$ & $0,59^{*}$ & $0,41^{*}$ \\
\hline
\end{tabular}

* Significativo ao nível de $5 \%$ de probabilidade. ** Significativo ao nível de $1 \%$ de probabilidade.

FIGURA 2: Intensidade fenológica: botão floral (a), floração (b), frutos verdes (c), frutos maduros (d), queda foliar (e) e brotação folha (f) de Sebastiania brasiliensis.

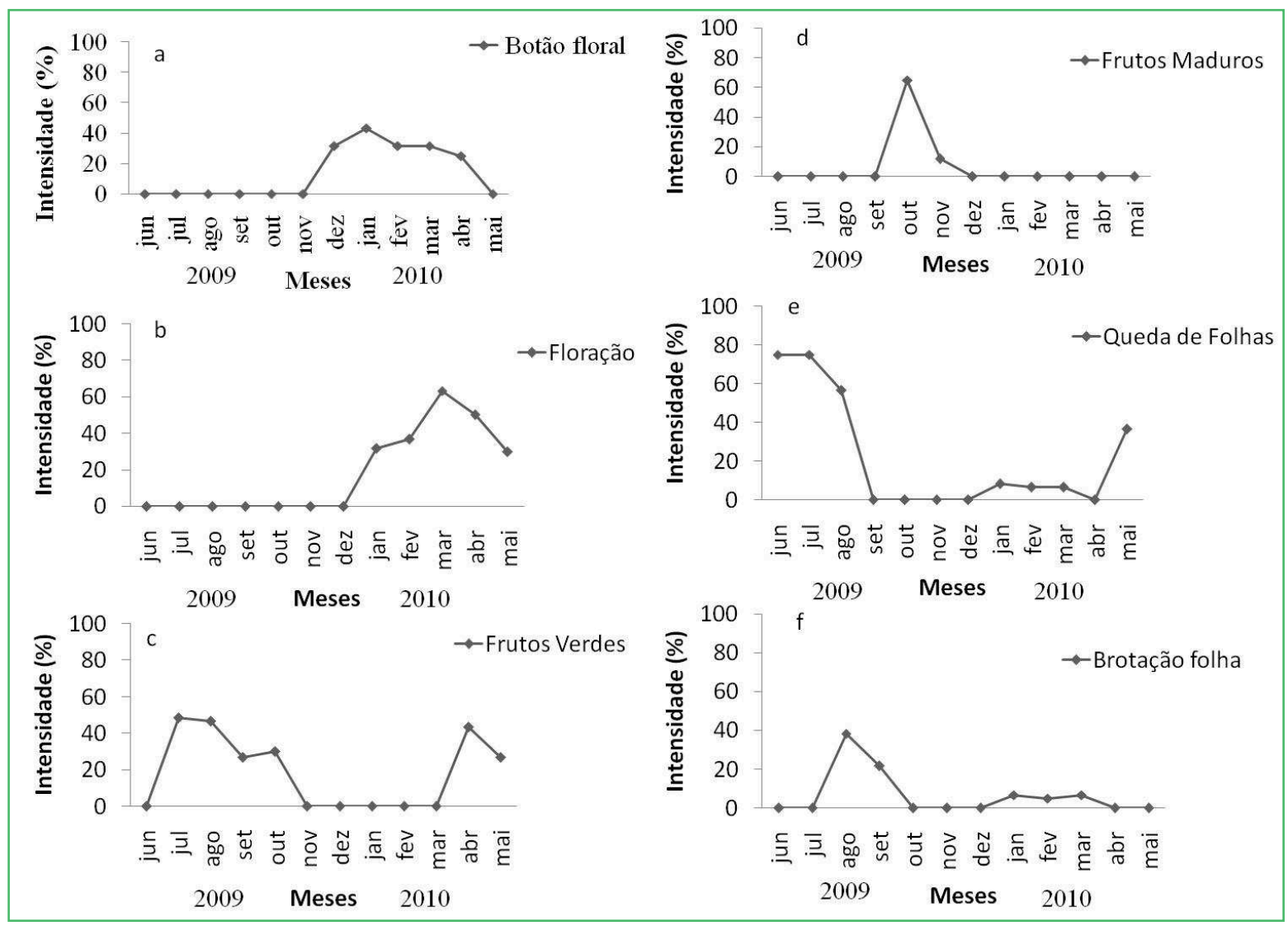


As fases de queda e brotação foliar não apresentaram correlação significativa com nenhuma variável climática. Mesmo não significativa, as correlações da fase queda foliar foram negativas para temperatura média, precipitação e comprimento do dia, indicando que com a diminuição dessas condições ambientais ocorre o aumento da queda foliar (Tabela 2). Já as brotações foliares tenderam a aumentar com a temperatura e comprimento do dia.

\section{Botões florais e floração}

Ambas as fases foram sazonais e com alta sincronia. $\mathrm{O}$ pico da atividade dos botões florais ocorreu em fevereiro, com alta concentração em torno da data média $(\mathrm{r}=0,76)$ (Tabela 1$)$. Após um mês ocorreu o pico da atividade da floração (março), também com alta concentração em torno da data média $(\mathrm{r}=0,76)$ (Tabela 1).

Os botões florais surgiram a partir de novembro, atingindo a maior intensidade em janeiro (43\%) e diminuindo a intensidade até não apresentar a fase no mês de abril (Figura 2a). Um mês depois do aparecimento dos primeiros botões florais, estes passaram para a fase de antese, que apresentou a maior intensidade no mês de março (63\%) e não foi mais observada no mês de maio (Figura 2b). Assim, nota-se que de um evento a outro ocorre um intervalo de um mês para que ocorra a abertura das flores e para que estas estejam prontas para serem polinizadas.
A fase botões florais não apresentou correlação significativa com as variáveis climáticas. Porém observase que os valores das correlações foram positivos, indicando que com o aumento da temperatura média, precipitação, umidade relativa e comprimento do dia também ocorre o aumento dessa fenofase. Mesmo comportamento observado para a fenofase floração (Tabela 2).

\section{Frutos imaturos e maduros}

Os frutos imaturos e maduros apresentaram sazonalidade, caracterizada pela ocorrência do evento fenológico uma vez ao ano, sendo que os frutos imaturos tiveram seu pico de atividade em julho. Estes, porém, apresentaram baixa sincronia $(r=0,48)$, enquanto os frutos maduros apresentaram alta sincronia, com $\mathrm{r}=$ 0,98, com o pico da atividade ocorrendo no mês de outubro (Tabela 1).

A fase de frutos imaturos apresentou dois picos de intensidade, um nos meses de julho e agosto e outro em abril (Figura 2c). Essa fase inicia no mês de abril, três meses após as primeiras floradas. A partir desse momento as flores vão sendo fecundadas e os frutos sendo produzidos até o mês de julho, quando se tem a maior intensidade. Após esse período, ocorre a diminuição da produção (Figura 2c). Do ponto de maior intensidade dos frutos imaturos até o ponto de maior intensidade dos frutos maduros, passaram três meses. Assim, os frutos maduros apresentaram a maior intensidade em outubro,

TABELA 2: Correlações de Spearman (rs) entre as fenofases e as variáveis climáticas de dois meses antes da ocorrência da fenofase (T. med.= temperatura média; UR\%= umidade relativa; precipitação e comprimento do dia), para Sebastiania brasiliensis.

\begin{tabular}{ccccc}
\hline Fenofases/Variáveis climáticas & T. med. & UR & Precipitação & Comprimento do dia \\
\hline Botão floral & $0,89^{\text {ns }}$ & $0,63^{\text {ns }}$ & $0,63^{\text {ns }}$ & $0,73^{\text {ns }}$ \\
Floração & $0,54^{\text {ns }}$ & $0,73^{\text {ns }}$ & $0,73^{\text {ns }}$ & $0,42^{\text {ns }}$ \\
Frutos imaturos & $-0,89^{\text {ns }}$ & $-0,89^{\text {ns }}$ & $0,23^{\text {ns }}$ & $-0,89^{\text {ns }}$ \\
Frutos maduros & $0,73^{\text {ns }}$ & $0,38^{\text {ns }}$ & $0,10^{\text {ns }}$ & $0,94^{\text {ns }}$ \\
Queda de folhas & $-0,81^{\text {ns }}$ & $-0,81^{\text {ns }}$ & $0,27^{\text {ns }}$ & $-0,81^{\text {ns }}$ \\
Brotação folha & $0,73^{\text {ns }}$ & $-0,32^{\text {ns }}$ & $-0,63^{\text {ns }}$ & $0,73^{\text {ns }}$ \\
\hline
\end{tabular}

\footnotetext{
${ }^{\text {ns }}$ não significativo.
} 
com $65 \%$, e diminuindo drasticamente em novembro, 12\% (Figura 2d).

As variáveis climáticas não apresentaram correlação significativa com a fenofase frutos imaturos e maduros. No caso da primeira fenofase, os valores das correlações foram negativos para temperatura, precipitação e comprimento do dia, ou seja, com a diminuição dessas variáveis aumenta a formação dos frutos imaturos. Por outro lado, os frutos maduros aumentam de quantidade com o aumento dessas variáveis climáticas; mesmo não sendo significativo estaticamente, o comprimento do dia com "rs" de 0,94 (valor-p de 0,06 ) foi o que mais influenciou essa fenofase (Tabela 2).

\section{Discussão}

A sazonalidade ocorreu (ângulo médio significativo na análise circular) para todas as fases de $S$. brasiliensis, com padrões fenológicos bem definidos. A fenofase vegetativa apresentou baixa sincronia, pois ocorre em um maior espaço de tempo. Enquanto a fenofase reprodutiva mostrou alta sincronia, com exceção da fase frutos imaturos. Autores como Marques et al. (2004) e Liebsch e Mikich (2009), considerando todas as formas de vida vegetal que compõem a Floresta Ombrófila Mista no sul do Paraná, também encontraram uma alta sazonalidade fenológica nos eventos reprodutivos.

Essa alta sincronia da fenofase reprodutiva é importante por fornecer informações práticas para projetos de restauração florestal, indicando o melhor momento de coletar frutos e sementes. No caso de $S$. brasiliensis, o período de floração até frutos imaturos é mais longo, porém, o do amadurecimento até a dispersão é curto, podendo prejudicar a coleta de sementes se não tiver o monitoramento adequado. Dessa forma, indica-se que o monitoramento seja mais frequente no início da primavera, para garantir coleta das sementes antes que ocorra a sua dispersão.

A fenofase reprodutiva ocorreu por um longo período de tempo, iniciando no mês de dezembro com os primeiros botões florais e chegando a flores formadas ou em antese no mês de março. Esse período em que se sucederam as primeiras fases reprodutivas coincidiu com o verão, o que, indiretamente, favorece a polinização, já que a disponibilidade de animais polinizadores é maior (VAN SCHAIK et al., 1993) e ocorre o aumento da temperatura, da precipitação e do comprimento do dia, podendo influenciar o florescimento (ALENCAR et al., 1979; MORELLATO, 1992). Isso pode ser evidenciado pela intensidade de frutos imaturos formados nos meses de julho e agosto após a fase da antese, na qual o período de transição foi de três meses, de um pico a outro. Assim, a fase de frutos verdes ocorreu por todo o inverno, período mais seco, atingindo a maturação em outubro, período de aumento das temperaturas e das precipitações, fazendo com que seu fruto do tipo explosivo (balistocórica - autocoria) disperse suas sementes, pela perda de umidade do fruto. A dispersão durante esse período de transição, inverno e primavera, pode ser uma estratégia, por possibilitar que seus frutos amadureçam, dispersem e germinem em melhores condições do solo (MORELLATO, 1991; VAN SCHAIK et al., 1993). Isso ocorre pois após esse período tem o aumento das chuvas, consequentemente, o aumento do nível do rio e do lençol freático, recobrindo o solo com água, condição que dificulta a germinação.

A brotação e a queda foliar foram consideradas sazonais para a população avaliada, porém não ocorreu a queda de $100 \%$ das folhas. Em florestas com disponibilidade hídrica constante, sem estação seca severa, a queda foliar e brotação contínua são estratégias mais vantajosas para a planta, por permitir translocação de nutrientes, a partir da folha velha para novas estruturas, e taxa fotossintética constante durante todo o ano (JACKSON, 1978). Diferentemente de espécies totalmente decíduas, que tem como estratégia a queda de $100 \%$ das folhas para interromper a evapotranspiração e garantir a sobrevivência durante a estação seca.

Sebastiania brasiliensis é semidecídua e típica de sub-bosque, podendo ser uma das espécies indicadas para restauração de áreas que necessitam de sombreamento ou cobertura do solo constante, para evitar a entrada de plantas competidoras invasoras ou a erosão do solo, por permanecer com folhas o ano todo. Dessa maneira, mesmo essa espécie apresentando pouca correlação com as variáveis climáticas estudadas no período, estas são as principais motivadoras dos padrões fenológicos 
dessa espécie e das espécies do mesmo ambiente, com destaque para temperatura e fotoperíodo (MORELLATO et al., 2000; MARQUES et al., 2004).

É importante também a utilização de outras variáveis climáticas que não foram avaliadas e são importantes para determinar as fenofases, tais como radiação solar e intensidade do vento; assim como a utilização de outro número de indivíduos amostrados, que poderia ser entre 20 a 30, e o monitoramento de outras regiões para ter maior representatividade da população.

Assim, durante a avaliação, S. brasiliensis apresentou padrões fenológicos vegetativos e reprodutivos bem definidos, ocorrendo uma vez durante $o$ ano avaliado. As fenofases reprodutivas apresentaram maior sincronia do que as fenofases vegetativas durante o tempo de acompanhamento. O que possibilita o planejamento de estratégias de monitoramento da fenologia da espécie e até mesmo excursões para a coleta de sementes para fins de restauração florestal.

\section{Referências}

ALENCAR, J. C.; ALMEIDA, R. A.; FERNANDES, N. P. Fenologia de espécies florestais em floresta tropical úmida de terra firme na Amazônia Central. Acta Amazonica, Manaus, v. 9, n. 1, p. 163-198, 1979.

ALENCAR, J. C. Estudos silviculturais de uma população natural de Copaifera multijuga Hayne - Leguminosae, na Amazônia Central IV. Interpretação de dados fenólogicos em relação a elementos climáticos. Acta Amazonica, Manaus, v. 18, n. 3-4, p. 199-209, 1988.

BARDDAL, M. L.; RODERJAN, C. V.; GALVÃO, F.; CURCIO, G. R. Caracterização florística e fitossociológica de um trecho sazonalmente inundável de floresta aluvial, em Araucária, PR. Ciência Florestal, Santa Maria, v. 14, n. 2, p. 37-50, 2004.

BAWA, K. S.; KANG, H.; GRAYUM, M. H. Relationships among time, frequency, and duration of flowering in Tropical Rain Forest Trees. American Journal of Botany, Columbus, v. 90, n. 6, p. 877887,2003

BELO, R. M.; NEGREIROS, D.; FERNANDES, G. W.; SILVEIRA, F. A. O.; RANIERI, B. D.; MORELLATO, P. C. Fenologia reprodutiva e vegetativa de arbustos endêmicos de campo rupestre na Serra do Cipó, Sudeste do Brasil. Rodriguésia, Rio de Janeiro, v. 64, n. 4, p. 817-828, 2013.

BENCKE, C. S. C.; MORELlATO, L. P. C. Comparação de dois métodos de avaliação da fenologia de plantas, sua interpretação e representação. Revista Brasileira de Botânica, São Paulo, v. 25, n. 3, p. 269-275, 2002.
BRITO NETO, R. L.; ARAUJO, E. I. P.; MACIEL, C. M. S.; PAULA, A.; TAGLIAFERRE, C. Fenologia de Astronium graveolens Jacq. em Floresta Estacional Decidual em Vitória da Conquista, Bahia. Ciência Florestal, Santa Maria, v. 28, n. 1, p. 641-650, 2018.

CURCIO, G. R. Relações entre Geologia, Geomorfologia, Pedologia e Fitossociologia nas planícies fluviais do rio Iguaçu, Paraná, Brasil. 2006. 488 f. Tese (Doutorado em Engenharia Florestal) - Universidade Federal do Paraná, Curitiba. 2006.

DAUBENMIRE, R. Phenology and other characteristics of tropical semi-deciduous forest in northwestern Costa Rica. Journal of Ecology, London, v. 60, n. 1, p. 147-170, 1972.

FERRERA, T. S.; PELISSARO, T. M.; EISINGER, S. M.; RIGHI, E. Z.; BURIOL, G. A. Fenologia de espécies nativas arbóreas na região central do estado do Rio Grande do Sul. Ciência Florestal, Santa Maria, v. 27, n. 3, p. 753-766, 2017.

FOURNIER, L. A. Un método cuantitativo para la medición de características fenológicas en árboles. Turrialba, San José, v. 24, n. 4, p. 422-423, 1974 .

FOURNIER, L. A.; CHARPANTIER, C. El tamaño de la muestra y la frecuencia de las observaciones en El estudio de las características fenológicas de los árboles tropicales. Turrialba, San José, v. 25, n. 1, p. $45-48,1975$.

FRANKIE, G. W.; HABER, H. G; OPLER, P. A. Comparative phenological studies of trees in tropical wet and dry forests in the lowlands of Costa Rica. Journal Ecology, London, v. 62, n. 3, p. 881-913, 1974.

JACKSON, J. F. Seasonality of flowering and leaf-fall in Brazilian subtropical Lower Montane Moist Forest. Biotropica, Malden, v. 10, n. 1, p.38-42, 1978.

$\mathrm{KOVACH}, \mathrm{W}$. L. Oriana version 3.0 for windows. Anglesey: Kovach Computing Services, 2010.

LIEBSCH, D.; MIKICH, S. B. Fenologia reprodutiva da Floresta Ombrófila Mista. Revista Brasileira de Botânica, São Paulo, v. 32, n. 2, p. 375-391, 2009.

MAACK, R. Geografia física do estado do Paraná. Curitiba: UEPG, 1968. 350 p.

MARQUES, M. C. M.; ROPER, J. J.; SALVALAGGIO, A. P. B. Phenological patterns among plant life-forms in a subtropical forest in southern Brazil. Plant Ecology, Dordrecht, v. 173, n. 2, p. $203-$ 213, 2004.

MEDRI, M. E.; BIANCHINI, E.; PIMENTA, J. A.; COLLI, S.; MULLER, C. Estudos sobre a tolerância ao alagamento em espécies arbóreas nativas da bacia do rio Tibagi. In: MEDRI, M. E.; BIANCHINI, E.; SHIBATTA, O. A.; PIMENTA, J. A. (Ed.). A bacia do rio Tibagi. Londrina: Edição dos Editores, 2002. p. 133-172.

MORELLATO, L. P. C. Estudo da fenologia de árvores, arbustos e lianas de uma floresta semidecídua no Sudeste do Brasil. 1991. 210 f. Tese (Doutorado em Ecologia) - Universidade Estadual de Campinas, São Paulo. 1991

MORELLATO, L. P. C. Sazonalidade e dinâmica de ecossistemas florestais na Serra do Japi. In: MORELLATO, L. P. C. (Org.). História natural da Serra do Japi - Ecologia e preservação de uma área de floresta no sudeste do Brasil. 1 Ed. Campinas: Unicamp/Fapesp, 1992. p. 98-110. 
MORELlato, L. P. C.; CAMARGO, M. G. G.; D'EÇA NEVES, F. F.; LUIZE, B. G.; MANTOVANI, A.; HUDSON, I. L. The influence of sampling method, sample size, and frequency of observations on plant phenological patterns and interpretation in tropical forest trees. In: HUDSON, I. L.; KEATLEY, M. (Ed.). Phenological research: methods for environmental and climate change analysis. Dordrecht: Springer, 2010. p. 99-121.

MORELLATO, L. P. C.; LEITÃO-FILHO, H. F.; RODRIGUES, R. R.; JOLY, C. A. Estratégias fenológicas de espécies arbóreas em floresta de altitude na Serra do Japi, Jundiaí São Paulo. Revista Brasileira de Biologia, São Carlos, v. 50, n. 1, p. 149-162, 1990.

MORELLATO, L. P. C.; RODRIGUEZ, R. R.; LEITÃO-FILHO, H. F. Estudo comparativo da fenologia de espécies arbóreas de floresta de altitude e floresta mesófila semidecídua na Serra do Japi, Jundiaí, São Paulo. Revista Brasileira de Botânica, São Paulo, v. 12, n. 1-2, p. 85-98, 1989.

MOREllato, L. P. C.; ROMERA, E. C.; TAlORA, D. C.; TAKAHASHI, A.; BENCKE, C. C.; ZIPPARRO, V. B. Phenology of Atlantic Rain Forest trees: a comparative study. Biotropica, Malden, v. 32, n. 4b, p. 811-823, 2000.
NEWSTROM, L. E.; FRANKIE, G. W.; BAKER, H. G. A new classification for plant phenology based on flowering patterns in lowland tropical rain forest trees at La Selva, Costa Rica. Biotropica, Malden, v. 26, n. 2, p. 141-159, 1994.

PILON, N. A. L.; UDULUTSCH, R. G.; DURIGAN, G. Padrões fenológicos de 111 espécies de Cerrado em condições de cultivo. Hoehnea, São Paulo, v. 42, n. 3, p. 425-443, 2015.

REITZ, R. Alto Biguaçu. Florianópolis: Editora Lunardelli e EDUFSC, 1988. 584 p.

RODRIGUES, R. R; GANDOLFI, S. Conceitos, tendências e ações a recuperação de florestas ciliares. In: RODRIGUES, R. R.; LEITÃO FILHO, H. F. (Ed.). Matas Ciliares - Conservação e Recuperação. 2. ed. São Paulo: EDUSP/FAPESP, 2004. p. 233-248. VAN SCHAIK, C. P.; TERBORGH, J. W.; WRIGTH, S. J. The phenology of tropical forests: adaptative significance and consequences for primary consumers. Annual Review of Ecology and Systematics, Palo Alto, v. 24, n. 1, p. 353-377, 1993.

ZAR, J. H. Biostatistical analysis. 4. ed. New Jersey: PrenticeHall, 1998. 929 p. 